\title{
A PÓS-GRADUAÇÃO EM EDUCAÇÃO E O PNE
}

\author{
M. M. MACHADO \\ Universidade Federal de Goiás - UFG \\ mmm2404@gmail.com
}

Artigo submetido em agosto/2016 e aceito em agosto/2016

DOI: 10.15628/holos.2016.5012

\section{RESUMO}

O objetivo desse texto é refletir sobre a Pós-Graduação no PNE 2014-2024, Lei 13.005/2014. Para tanto, situar essa discussão a partir de que concepção epistemológica e política com destaque a tensão entre as relações Estado e da Sociedade Civil, numa concepção de Estado Ampliado, que retomam e reafirmam projetos de educação e de sociedade em disputa. O que nos leva a concluir que os desafios concernentes ao PNE tem uma dimensão política: ser a referência para a política educacional, em tempos de atravessamentos múltiplos entre as ações indutivas da Secretaria de Assuntos Estratégicos da Presidência da República e uma dimensão econômica: implementar estratégias das 20 metas do PNE sob forte impacto no orçamento da união, dos estados e municípios do contingenciamento dos recursos para a área da Educação.

PALAVRAS-CHAVE: Pós-Graduação. PNE 2014-2024. Brasil.

\section{THE GRADUATE DIPLOMA IN EDUCATION AND THE PNE}

\section{ABSTRACT}

The objective of this text is reflecting on the Graduation course on PNE 2014-2024, Decree n. 13.005/2014. So, we place this discussion from the epistemological and political conception emphasizing the tension between the State and the Civil Society into a conception of Expanded State that returns and reassures the projects of education and Society under dispute. What leads us to concluding that the challenges concerning PNE has a political dimension: to be the reference for the educational policy in times of multiple crossings between inductive actions from the Office of Strategical Issues of the Republic Preisdency (Secretaria de Assuntos Estratégicos da Presidência da República) and an economical dimension: to implement strategies for the PNE 20 goals under the strong impact on the budget of the country, states and cities of the allocation of the resources for Education.

KEYWORDS: Graduation course. PNE 2014-2024. Brazil. 


\section{INTRODUÇÃO}

Inicio esta reflexão agradecendo o convite e a oportunidade de participar pela terceira vez deste Colóquio A produção do Conhecimento em Educação Profissional: O Plano Nacional de Educação (2014-2024). No II Colóquio, em 2013, estive numa mesa com Domingos ${ }^{1}$ - Proeja: da compensação à formação humana integral; no I Colóquio em 2011, Educação de Jovens e Adultos - o diálogo fundamental com educação profissional e o desafio de visibilidade na pós-graduação. Neste de 2015, a solicitação feita pela equipe de organização deste importante evento científico foi de trazer algumas reflexões sobre a Pós-Graduação no PNE 2014-2024, Lei 13.005/2014 aprovada há um ano.

Antes de entrar propriamente no tema, gostaria de destacar a riqueza que deve ter sido para alunos e pesquisadores da área da educação profissional poder dialogar, nestes dias, com colegas que fazem a história da educação profissional no país, socializando o que efetivamente produzem em termos de conhecimentos numa área que envolve um compromisso ético-político com a classe trabalhadora, com a formação da juventude brasileira e com a formação de adultos trabalhadores. Lamento não ter conseguido acompanhar as mesas anteriores, pois tenho aprendido muito com todos estes pesquisadores e costumo dizer que, se houve um ganho do ponto de vista da produção do conhecimento para quem pesquisa EJA no país foi o Proeja possibilitar nossa aproximação com tantos colegas do campo do Trabalho e Educação, onde o foco das reflexões da formação humana integral muito tem nos alimentado.

Cabe a nós aqui neste encerramento, retomar este campo ampliado de formação humana, formação para o trabalho e constituição cidadã, numa leitura do Plano Nacional de Educação. Não é apenas uma lei. É a expressão de um campo em disputa, dado que sua materialidade, da elaboração a sua concretude, envolve os diferentes atores que atuam na cena da educação nacional, com seus múltiplos interesses e concepções. Portanto, não é possível pensar o que ele traz de desafios para a pós-graduação, sem considerarmos que estamos diante de uma Lei viva, em movimento, cuja efetividade dependerá em grande parte dos atores envolvidos.

Para entrar então, propriamente no tema do $\mathrm{PNE}^{2}$, cabe-me situar a partir de que concepção epistemológica e política trato o tema que me foi proposto para esta conferência: uma clara tensão entre as relações Estado e da Sociedade Civil, numa concepção de Estado Ampliado, que retomam e reafirmam projetos de educação e de sociedade em disputa. Diria que só é possível tratá-lo, no contexto atual, acompanhada de Antonio Gramsci, militante do Partido Comunista Italiano, quando no início do século XX assume em suas reflexões a expressão de um romancista francês, para dizer o que sentia diante da conjuntura política em seu país "pessimismo da inteligência, otimismo da vontade"3. Esta posição de Gramsci é também evidente, quando analisa

\footnotetext{
${ }^{1}$ Domingos Leite Lima Filho

${ }^{2}$ No periodo de final de 2013 a final de 2015, estando como Presidente da Anped, foram muitas as ocasiões em que tive a oportunidade de proferir palestras, participar em mesas e conferências, manifestando minha compreensão sobre as relações entre a Pós-Graduação e o Plano Nacional de Educação. A cada convite busquei aproximar a reflexão do público-alvo, o que não me eximiu de ser reiterativa em algumas convicções, sobretudo as que orientam conceitualmente como me posiciono frente ao tema. Todavia, em respeito a pluralidade de ideias existente nessa associação, reafirmo que estas reflexões são as que estão ao meu alcance e pelas quais assumo sua autoria.

${ }^{3}$ Frase de Romain Rolland (Clamecy, 29 de janeiro de 1866 - Vézelay, 30 de dezembro de 1944) foi um novelista, biógrafo e músico francês. Recebeu o Nobel de Literatura de 1915.
} 
os temas essenciais à civilização moderna, dentre eles, o racionalismo iluminista e o voluntarismo romântico. Sua crítica ao primeiro pelo ceticismo aristocrático e ao segundo pelo individualismo desordenado, repõe como alternativa "a tentativa de conjugar de modo novo razão e vontade, criticismo coerente e capacidade de incidir nos processos reais do mundo".

Penso que esta postura tem uma forte relação com o contexto que vivemos no país, e o que ele ainda exige de nós. Estamos acompanhando e sofrendo os impactos diretos de uma política econômica, com base em ajustes fiscais, utilizada para justificar os vários cortes do orçamento federal em todas as áreas, sobretudo na área da educação. Não poderíamos então, dar início a esta conferência sem mencionar que a liberação de $25 \%$ do orçamento previsto para o custeio das atividades dos programas de pós-graduação, feito agora em julho, implica numa medida de desrespeito ao trabalho que ocorreu em todo o primeiro semestre deste ano, pois a maioria dos programas não consegue sequer saldar suas dívidas acumuladas de janeiro a julho de 2015, em especial com as despesas de passagens e diárias que são as prioridades para garantir pelo menos a realização das bancas, quiçá a garantia de participação em eventos científicos para socialização dos conhecimentos gerados pelas pesquisas. Portanto, entendo ser este o primeiro desafio a enfrentarmos no PNE, não apenas no que diz respeito a Pós-Graduação, mas, sem dúvida, também naquilo que estava previsto em relação a sua consolidação e expansão para os próximos 10 anos. Há diversas manifestações a este respeito, chamo a atenção para as notas publicadas pela ANPEd em seu site e que cobram do Ministério da Educação medidas urgentes para rever os cortes anunciados.

\section{A PÓS-GRADUAÇÃO NO PNPG/2010 E NO PNE/2014}

Para esta reflexão sobre o PNE, é importante considerar que no âmbito da Pós-Graduação, paralelo ao intenso debate em torno da Conferência Nacional de 2010, estava em curso a discussão do Plano Nacional de Pós-Graduação (PNPG 2011-2020), editado em novembro de 2010 pela Fundação Coordenação de Aperfeiçoamento de Pessoal de Nível Superior (CAPES), e que tem como objetivo definir novas diretrizes, estratégias e metas para dar continuidade e avançar nas propostas para a política de pós-graduação e pesquisa no Brasil. O texto do PNPG informa que pela primeira vez, um plano no âmbito da pós-graduação integrará o PNE e, com certeza, esta menção se refere à Meta 14 deste plano que é dedicada totalmente ao tema.

Chamo a atenção para o PNPG, por considerar que as reflexões explicitadas nos seus Volumes I e II, traduzem as contradições que vivemos no debate em torno da pós-graduação no país, sobretudo se nos ativermos aos textos publicados como documentos setoriais, onde o reconhecimento do crescimento da pós-graduação no país, nos últimos 15 anos, segue ao lado da crítica de um modelo de mestrados acadêmicos esvaziados de sentido, e a pouca inovação e produção voltada para o avanço tecnológico e a serviço das exigências de mercado. Como são temáticas bem polêmicas, sobretudo para nós da área da Educação, sugiro que estes documentos sejam lidos, até para que possamos compreender melhor o foco que acaba por tomar a cena de tramitação do PNE, nos seus três anos e meio, sua aprovação no congresso nacional e sua sanção sem vetos pela Presidenta Dilma. Para esta conferência, optei por destacar algumas das leituras possíveis do que está no PNE e as discussões que aparecem no PNPG.

O texto aprovado na Lei 13.005/2014 (BRASIL, 2014), nos seus 14 artigos, não faz referência explícita a pós-graduação, isto vai aparecer quando analisamos o Anexo onde constam as 20 metas 
e 254 estratégias. O tema da pós-graduação aparece explicitamente em duas metas: 14 e 16, em específico e em, pelo menos, 7 estratégias espalhadas em outras metas. 0 texto mais direcionado a pós-graduação está na Meta 14 que conta com 15 estratégias:

Meta 1 - Meta 1: universalizar, até 2016, a educação infantil na pré-escola para as crianças de 4 (quatro) a 5 (cinco) anos de idade e ampliar a oferta de educação infantil em creches de forma a atender, no mínimo, 50\% (cinquenta por cento) das crianças de até 3 (três) anos até o final da vigência deste PNE.

1.9) estimular a articulação entre pós-graduação, núcleos de pesquisa e cursos de formação para profissionais da educação, de modo a garantir a elaboração de currículos e propostas pedagógicas que incorporem os avanços de pesquisas ligadas ao processo de ensino-aprendizagem e às teorias educacionais no atendimento da população de 0 (zero) a 5 (cinco) anos;

\section{$[\ldots]$}

Meta 4 - Meta 4: universalizar, para a população de 4 (quatro) a 17 (dezessete) anos com deficiência, transtornos globais do desenvolvimento e altas habilidades ou superdotação, o acesso à educação básica e ao atendimento educacional especializado, preferencialmente na rede regular de ensino, com a garantia de sistema educacional inclusivo, de salas de recursos multifuncionais, classes, escolas ou serviços especializados, públicos ou conveniados.

4.16) incentivar a inclusão nos cursos de licenciatura e nos demais cursos de formação para profissionais da educação, inclusive em nível de pós-graduação, observado o disposto no caput do art. 207 da Constituição Federal, dos referenciais teóricos, das teorias de aprendizagem e dos processos de ensinoaprendizagem relacionados ao atendimento educacional de alunos com deficiência, transtornos globais do desenvolvimento e altas habilidades ou superdotação;

\section{$[\ldots]$}

Meta 5: alfabetizar todas as crianças, no máximo, até o final do 30 (terceiro) ano do ensino fundamental.

5.6) promover e estimular a formação inicial e continuada de professores (as) para a alfabetização de crianças, com o conhecimento de novas tecnologias educacionais e práticas pedagógicas inovadoras, estimulando a articulação entre programas de pós-graduação stricto sensu e ações de formação continuada de professores (as) para a alfabetização;

\section{$[\ldots]$}

Meta 12: elevar a taxa bruta de matrícula na educação superior para $50 \%$ (cinquenta por cento) e a taxa líquida para 33\% (trinta e três por cento) da população de 18 (dezoito) a 24 (vinte e quatro) anos, assegurada a qualidade da oferta e expansão para, pelo menos, $40 \%$ (quarenta por cento) das novas matrículas, no segmento público. 
12.12) consolidar e ampliar programas e ações de incentivo à mobilidade estudantil e docente em cursos de graduação e pós-graduação, em âmbito nacional e internacional, tendo em vista o enriquecimento da formação de nível superior;

\section{$[\ldots]$}

Meta 13: elevar a qualidade da educação superior e ampliar a proporção de mestres e doutores do corpo docente em efetivo exercício no conjunto do sistema de educação superior para $75 \%$ (setenta e cinco por cento), sendo, do total, no mínimo, 35\% (trinta e cinco por cento) doutores.

13.5) elevar o padrão de qualidade das universidades, direcionando sua atividade, de modo que realizem, efetivamente, pesquisa institucionalizada, articulada a programas de pós-graduação stricto sensu;

\section{$[\ldots]$}

Meta 16: formar, em nível de pós-graduação, $50 \%$ (cinquenta por cento) dos professores da educação básica, até o último ano de vigência deste PNE, e garantir a todos (as) os (as) profissionais da educação básica formação continuada em sua área de atuação, considerando as necessidades, demandas e contextualizações dos sistemas de ensino.

16.5) ampliar a oferta de bolsas de estudo para pós-graduação dos professores e das professoras e demais profissionais da educação básica;

\section{$[\ldots]$}

Meta 18: assegurar, no prazo de 2 (dois) anos, a existência de planos de Carreira para os (as) profissionais da educação básica e superior pública de todos os sistemas de ensino e, para o plano de Carreira dos (as) profissionais da educação básica pública, tomar como referência o piso salarial nacional profissional, definido em lei federal, nos termos do inciso VIII do art. 206 da Constituição Federal.

18.4) prever, nos planos de Carreira dos profissionais da educação dos Estados, do Distrito Federal e dos Municípios, licenças remuneradas e incentivos para qualificação profissional, inclusive em nível de pós-graduação stricto sensu; (BRASIL, 2014)

Cabe um estudo mais aprofundado da Meta 14.

Meta 14: elevar gradualmente o número de matrícula na pós-graduação stricto sensu, de modo a atingir a titulação anual de 60.000 (sessenta mil) mestres e 25.000 (vinte e cinco mil) doutores.

Estratégias:

14.1) expandir o financiamento da pós-graduação stricto sensu por meio das agências oficiais de fomento; 
14.2) estimular a integração e a atuação articulada entre a Coordenação de Aperfeiçoamento de Pessoal de Nível Superior - CAPES e as agências estaduais de fomento à pesquisa;

14.3) expandir o financiamento estudantil por meio do Fies à pós-graduação stricto sensu;

14.4) expandir a oferta de cursos de pós-graduação stricto sensu, utilizando inclusive metodologias, recursos e tecnologias de educação a distância;

14.5) implementar ações para reduzir as desigualdades étnico-raciais e regionais e para favorecer o acesso das populações do campo e das comunidades indígenas e quilombolas a programas de mestrado e doutorado;

14.6) ampliar a oferta de programas de pós-graduação stricto sensu, especialmente os de doutorado, nos campi novos abertos em decorrência dos programas de expansão e interiorização das instituições superiores públicas;

14.7) manter e expandir programa de acervo digital de referências bibliográficas para os cursos de pós-graduação, assegurada a acessibilidade às pessoas com deficiência;

14.8) estimular a participação das mulheres nos cursos de pós-graduação stricto sensu, em particular aqueles ligados às áreas de Engenharia, Matemática, Física, Química, Informática e outros no campo das ciências;

14.9) consolidar programas, projetos e ações que objetivem a internacionalização da pesquisa e da pós-graduação brasileiras, incentivando a atuação em rede e o fortalecimento de grupos de pesquisa;

14.10) promover o intercâmbio científico e tecnológico, nacional e internacional, entre as instituições de ensino, pesquisa e extensão;

14.11) ampliar o investimento em pesquisas com foco em desenvolvimento e estímulo à inovação, bem como incrementar a formação de recursos humanos para a inovação, de modo a buscar o aumento da competitividade das empresas de base tecnológica;

14.12) ampliar o investimento na formação de doutores de modo a atingir a proporção de 4 (quatro) doutores por 1.000 (mil) habitantes;

14.13) aumentar qualitativa e quantitativamente o desempenho científico e tecnológico do País e a competitividade internacional da pesquisa brasileira, ampliando a cooperação científica com empresas, Instituições de Educação Superior - IES e demais Instituições Científicas e Tecnológicas - ICTs;

14.14) estimular a pesquisa científica e de inovação e promover a formação de recursos humanos que valorize a diversidade regional e a biodiversidade da região amazônica e do cerrado, bem como a gestão de recursos hídricos no semiárido para mitigação dos efeitos da seca e geração de emprego e renda na região;

14.15) estimular a pesquisa aplicada, no âmbito das IES e das ICTs, de modo a incrementar a inovação e a produção e registro de patentes. (BRASIL, 2014) 
O cenário nacional para o alcance desta meta nos aponta o seguinte:

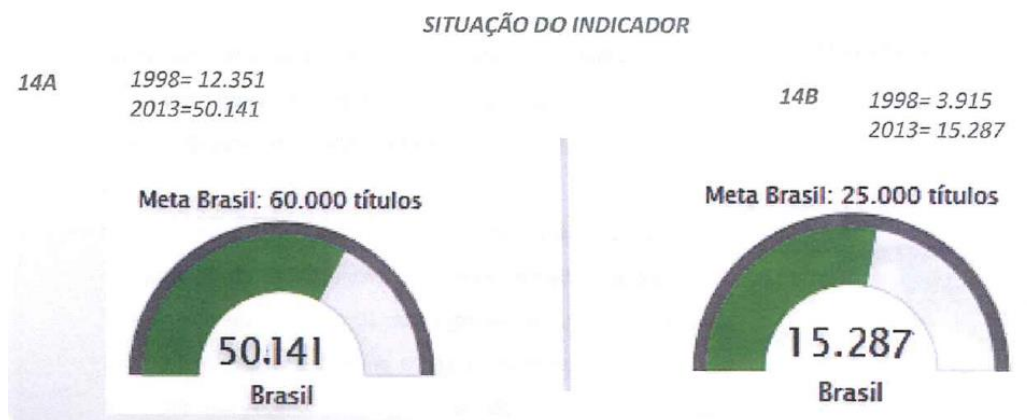

O INEP, através da Diretoria de Estudos Educacionais (Dired), entregou ao Fórum Nacional da Educação (FNE), à comissão de educação da Câmara e do Senado e ao Conselho Nacional de Educação (CNE), documento intitulado: Plano Nacional de Educação PNE 2014-2024 - Síntese da Linha de Base, com alguns comentários que precisam ser reconsiderados ao tratarmos da pósgraduação nesse Plano.

Com base nos dados apresentados, é possível afirmar que a meta de 60.000 mestres titulados por ano, não deverá apenas ser alcançada, mas efetivamente superada, pois se nos 15 anos anteriores à aprovação do PNE 2014-2024 este índice mais do que quadruplicou, titular 9.000 mestres a mais só vai se tornar uma meta impossível se a crise que estamos vivendo de fato paralisar o sistema de pós-graduação. Há quem avalie de forma negativa esta nossa titulação nos mestrados, que em sua maioria são mestrados acadêmicos, nas reflexões presentes no Volume II (BRASIL, 2010) do Plano Nacional de Pós-Graduação (2011-2020), onde se encontram os vários documentos setoriais, discutindo o futuro da Pós-Graduação até 2020 estas críticas são evidenciadas.

Autores como Maria Hermínia Tavares de Almeida e Simon Schwartzman, defendem abertamente o fim dos mestrados acadêmicos. A primeira, defende o doutorado como objetivo da formação pós-graduada, onde o título de mestre poderia ser concedido ao se cumprir uma etapa do doutorado. Defende ainda o fim do mestrado acadêmico e o mestrado profissional como única modalidade de formação final neste estágio. Já Schwartzman, além da defesa intensa da abertura da pós-graduação para o capital privado, de indicação de cobrança de anuidades nas instituições públicas e privadas, reafirma as críticas aos mestrados acadêmicos;

Desde o início, o Brasil criou uma anomalia, que é o mestrado acadêmico. Em todo o mundo, os mestrados são cursos de curta duração - entre um e dois anos - que visam dar uma formação adicional para preparar melhor os estudantes para o mercado de trabalho. No Brasil, os mestrados foram criados em grande parte como "mini-doutorados" por universidades que ainda não dispunham de massa crítica suficiente para instituir programas de doutoramento. Como "minidoutorados", os mestrados exigiam trabalhos de pesquisa e elaboração de teses que prolongavam os cursos e tinham pouca relação com a formação profissional, e foram adotados como preparação prévia e requerimento necessário para os doutorados. O reconhecimento deste problema levou à criação dos mestrados profissionais, que no entanto jamais conseguiram se estabelecer em volume suficiente. (BRASIL, 2010, p. 36-37) 
A discussão sobre o fim ou não dos mestrados acadêmicos está na ordem do dia. Não é uma estratégia tratada no PNE, mas seguramente os argumentos de redução de prazos para as defesas e a apresentação de resultados aplicáveis das pesquisas, em grande medida, contribuem para que o modelo de mestrado profissional siga sendo defendido como o que melhor se adéqua às necessidades da educação, sobretudo quando se trata da defesa de que este é o modelo ideal para a formação dos professores da educação básica. A estes é atribuída a falta de tempo e liberação para se qualificarem, ao passo que há quem os avalie como profissionais da educação que não demandariam uma formação acadêmica tão rigorosa, como se exige nos mestrados acadêmicos e doutorados. Sé mesmo possível concordar com tais avaliações? Qualquer exercício do pensar, mesmo que seja do pensar a sua prática não está efetivamente carregado de uma exigência teórica, conceitual, rigorosa e, portanto, acadêmica?

Esta questão de ampliação do acesso e conclusão dos mestrados, no ritmo previsto pelo $\mathrm{PNE}$, parece bem melhor equacionado do que o proposto para o doutorado. Pois o alcance da meta de 25.000 titulados ao ano implica numa ampliação de mais cerca de 10.000 doutores. Não é possível alcançar esta meta sem pensar na ampliação da oferta de doutorado no país, o que nos leva a uma outra discussão no âmbito da PNPG que tem a ver com o que se compreende por ampliação e interiorização da pós-graduação no Brasil.

No âmbito do PNPG, há quem defenda a ampliação e interiorização da pós-graduação, numa perspectiva que difere da eliminação dos mestrados, ficando a pós-graduação apenas como doutoramento, ou ainda a substituição dos mestrados acadêmicos pelos profissionais, como é o caso de Ana Lúcia Almeida Gazzola e Ricardo Fenati, que também neste Vol. Il do PNPG, num dos documentos setoriais vão afirmar:

O desenvolvimento da pós-graduação brasileira reflete as formas de organização da economia nacional, concentrando-se a maioria dos programas de mestrado e doutorado nas grandes cidades e nas regiões Sudeste e Sul. [...] Para que a pósgraduação brasileira responda de maneira adequada às necessidades de desenvolvimento do país, é fundamental que haja um espalhamento equilibrado e generoso de nosso parque científico em pontos estratégicos do vasto território brasileiro. Para tanto, não basta utilizar as tecnologias de educação à distância, criar novas universidades ou campi, pois a pós-graduação de qualidade requer tempo de maturação institucional, infraestrutura laboratorial complexa e de alto custo, grande número de pesquisadores produtivos e ambiente consolidado de pesquisa. Um douto não se forma ao receber o título: ser verdadeiramente um doutor, um líder em pesquisa, requer anos de trabalho, pares do mesmo nível, constituição de equipes. [...]

O movimento de interiorização da competência em pesquisa e pós-graduação, para que ganhe escala e aceleramento no tempo, requer um enfoque estratégico, com metas claras e instrumentos de premiação para aquelas instituições consolidadas dispostas a cooperar efetivamente para a consolidação de outras instituições.

[...] Não basta que um programa tenha atingido excelência em seu campo, é necessário que essa excelência se estenda a outros programas através de uma parceria responsável, estratégica e produtiva. [...] Ilhas de competência, como a história atesta, raramente são portadoras de futuro. Ao contrário, parodiando o 
que Marx disse a propósito do Capital, a excelência efetiva é excelência espalhada. (BRASIL, 2010, p. 11-12)

Retomando as duas principais reflexões acima, agora mais voltada a nossa área da educação, cabe perguntar que modelo de pós-graduação defendemos e como efetivaremos a proposta de ampliação do acesso e titulação na área da educação. Precisamos nos perguntar sobre isto, porque temos papel determinante nos rumos desta decisão, dado que deverão nos últimos anos implementar a PNPG os programas de pós-graduação de todo o país e o farão a partir das opções políticas e teóricas que defendem. Digo isto às vésperas dos seminários de acompanhamento com coordenadores de programas de pós-graduação, convocados pela Capes, onde a área da Educação se reunirá com o Coordenador, professor Romualdo Portela nos dias 19 a 21 de gosto, e tratará de temas, como por exemplo, nossa relação com os programas da Área de Ensino, a diferenciação entre mestrados acadêmicos e profissionais, a internacionalização, a produção qualificada, a nossa inserção social, entre outros.

Estes temas que serão objeto da discussão dos nossos coordenadores de programas e o Professor Romualdo, seguramente se desdobrarão em ações implementadas no âmbito da Capes, que conformarão mudanças ou não no modelo de pós-graduação na direção do que prevê o PNPG. Neste contexto, pensar a Pós-graduação e o PNE, só é possível se, voltando ao arcabouço teórico mencionado no início da fala, conseguirmos repor a discussão do Estado Ampliado e das condições objetivas para diante do "pessimismo da inteligência", mantermos o "otimismo da vontade". O PNE precisa ser encarado por nós como uma lei em movimento e em disputa. Para isto, cabe uma retomada ao que diz Cury a respeito

[...] a importância da lei não é identificada e reconhecida como um instrumento linear ou mecânico de realização de direitos sociais. Ela acompanha o desenvolvimento contextuado da cidadania em todos os países. A sua importância nasce do caráter contraditório que a acompanha: nela sempre reside uma dimensão de luta. Luta por inscrições mais democráticas, por efetivações mais realistas, contra descaracterizações mutiladoras, por sonhos de justiça. Todo o avanço da educação escolar além do ensino primário foi fruto de lutas conduzidas por uma concepção democrática da sociedade em que se postula ou a igualdade de oportunidades ou mesmo a igualdade de condições sociais. (CURY, 2002, p. 247)

Retomando as ponderações de Jamil Cury, toda lei é fruto de luta dos atores sociais na defesa de uma causa. A isto devemos estar atentos, pois as matérias das quais se ocupam nossos vereadores, deputados e senadores, dentro de uma República Federativa, são resultantes efetivas dos interesses de diferentes atores sociais. O autor afirma ainda que, no caso da educação, tudo o que alcançamos, até o momento, foi resultado destas lutas em prol da garantia da igualdade de oportunidades. Nossas lutas ultrapassam os limites do congresso e se materializam no interior das universidades pela via das Pró-Reitorias de Pós-Graduação e ainda nossos estados na negociação com as agências de fomento; no interior do MEC pela mediação de sua principal agência de fomento à pesquisa a Capes; ainda no âmbito federal, nos coloca diante dos desafios de ocupar a cena da Ciência e Tecnologia, no âmbito do CNPq.

Revisitar estas lutas do ponto de vista histórico, no nosso caso específico da pós-graduação contribui para situar quais são os principais desafios postos para que este PNE tenha um desfecho 
diferente do que ocorreu com o anterior, onde pouquíssimos foram os impactos na melhoria da educação como um todo. Só para repor o nosso desafio que é histórico, mas de um tempo ainda curto em termos de consolidação de políticas públicas, passados 54 anos da aprovação da primeira lei nacional dedicada a normatizar a educação brasileira, Lei 4024/61, devemos reconhecer que há rupturas e continuidades no cenário da luta política pela defesa da educação brasileira. Voltando a Gramsci, o pessimismo da inteligência, ou o pessimismo da razão, explicitam que os problemas da educação não estão circunscritos a disputa entre público e privado, que tomou a cena nos anos de debate desta primeira LDB. É preciso que se descortine o que está em questão, que se complexifique esta relação, mostrando sua espessura, para enquanto problema real, aí sim, num otimismo da vontade, buscarmos seu enfrentamento "Só a explicação racional dos processos pode produzir uma ação incisiva, uma vontade inflexível.", insistia o autor italiano.

Não cabe desconsiderá-la, a questão público privado ainda está em cena, inclusive nas entre linhas do debate do PNPG. Todavia, é fundamental situá-la no contexto das relações de interesses, dos projetos em disputa e das formas de mobilização e organização dos atores envolvidos nesta trama, eminentemente política, que vai ser resultante do debate pós Conferência Nacional de Educação 2010 e acompanha todo processo de tramitação e aprovação da Lei 13.005/2014 e segue presente nos debates da Conferência Nacional de 2014.

O contexto de lutas históricas que produziu a Lei 4024/61, desde os manifestos de 1932 e 1959; às conferências brasileiras de educação ${ }^{4}$ e congressos nacionais de educação 5 promovidos pela sociedade civil; à chegada à Conferência Nacional de Educação de 2010, nos permite afirmar que este é o PNE 2014-2024 é o primeiro que resulta dos embates criados, no espaço de uma conferência convocada pelo Estado, com participação da sociedade civil. Esta é a conjuntura que difere, em alguma medida, dos movimentos anteriores, cuja resultante fora sempre de propostas polarizadas, a exemplo do que ocorreu com os projetos apresentados ao Congresso em 2000 e que resultaram no PNE 2001-2010.

Dito isto, não significa apenas constar mudanças na correlação de forças sociedade política/ sociedade civil, estabelecidas sobretudo na última década, mas cabe tensionar de que sociedade política e civil estamos falando no contexto daquela conferência de 2010 e no contexto atual. É preciso reconhecer que, após 2003, com a posse do Presidente Lula, muitos dos professores, pesquisadores, gestores, militantes dos movimentos em defesa da educação pública, gratuita, laica e para todos, trocaram de "papéis" no Estado Ampliado. Saindo do espaço das entidades e instituições da sociedade civil e assumindo os cargos no âmbito da sociedade política. Passando de formuladores e defensores de concepções e princípios, que deveriam se materializar em políticas, a executores de um programa de governo, através de ações, projetos e programas vinculados a instrumentos, previstos num Plano Plurianual. Eu diria que foi o momento em que o pessimismo da razão deu espaço ao otimismo da vontade, e a pauta da educação, sobretudo no ministério se viu tencionada de alguma forma.

Por outro lado, é fruto também das políticas implementadas pelos últimos governos, o fortalecimento de entidades e organizações, algumas ditas sem fins lucrativos, que cada vez mais

\footnotetext{
${ }^{4} \mathrm{Na}$ década de 1980 foram realizadas seis Conferências Brasileiras de Educação (CBE), sendo: I CBE, 1980 - São Paulo; II CBE, 1982 - Belo Horizonte; III CBE, 1985 - Niterói; IV CBE, 1986 - Goiânia; V CBE, 1988 - Brasília; e VI CBE, 1991 São Paulo.

${ }^{5}$ Foram realizados cinco Congressos Nacionais de Educação (Coneds), sendo: I Coned, 1996 - Belo Horizonte; II Coned, 1997 - Belo Horizonte; III Coned, 1999 - Porto Alegre; IV Coned, 2003 - São Paulo; V Coned, 2004 - Recife.
} 
interferem na concepção e implementação da pauta educacional no país. Isto é visível, e as pesquisas que analisam as políticas educacionais, na sua relação com financiamento público, tem demonstrado que da Educação Infantil à Pós-Graduação, há uma expansão de acesso a educação, com forte financiamento público a instituições não públicas. Os dois exemplos mais claros nestes últimos anos estão nos programas Prouni e Pronatec, mas os recursos investidos também em iniciativas como a aplicação do ENEM, nos fazem perguntar quem se beneficia com a elaboração de itens, com a aplicação e correção de provas, quanto esta estratégia custa aos cofres públicos.

É possível identificar, também por meio das pesquisas, o esforço de expansão da rede pública de educação superior e profissional; cabe destaque as ações implementadas a partir das políticas de cotas, do Reuni e, porque não lembrar do próprio Ciências Sem Fronteira (abrindo aqui um parêntese para este último, que segue excluindo da possibilidade de bolsas para a grande maioria da área das Ciências Humanas, dentro dela a área da Educação). Ainda assim, exemplos em sua maioria ainda voltados para aqueles poucos que, no país, já concluíram Ensino Médio e buscam acesso ao Ensino Superior. Mas, não podemos deixar de reconhecer, o pessimismo da razão não nos permite isto, que há ainda um problema de base que estas iniciativas não atingiram: chegamos a Conferência Nacional de 2010 com mais de 13 milhões de brasileiros que já tem 15 anos e mais e não estão alfabetizados. Os dados do Censo de 2010 revelam o tamanho do desafio.

Apenas para destacar alguns destes números: quase 4 milhões e meio de adolescentes de 15 a 17 anos ainda não concluíram o Ensino Fundamental, eles fazem parte da população de 65 milhões de brasileiros que não tem 8 anos de escolaridade completa. Os que não possuem Ensino Médio são 27,5 milhões; 37 milhões tem 18 anos e mais e não possuem curso superior. Estes dados revelam o tamanho do desafio de expansão da escolaridade no Brasil, para a população de 15 anos e mais, que não por acaso é a população de jovens e adultos trabalhadores não escolarizados deste país. População esta que mobiliza parte significativa das nossas pesquisas no campo do Trabalho e Educação, incluindo aí a Educação de Jovens e Adultos e a Educação Profissional, como todos devem ter percebido nos debates ao longo deste colóquio.

Neste sentido, compreendemos que o desafio da ampliação da Pós-Graduação prevista no PNPG e reiterada no PNE, diante da realidade dos trabalhadores brasileiros, mais do que provar estatisticamente que é alcançável, nos coloca repõe um velho dilema: a serviço de quem e de que está o conhecimento que produzimos em nossas pesquisas na pós-graduação em educação? Em que medida nossas estratégias metodológicas de pesquisa contribuem para que os sujeitos envolvidos de fato se sintam produtores de conhecimento? Qual é a concepção de homem, sociedade e mundo que nos orienta no ato ético-político de pesquisar? Não são questões que diferem da compreensão da Lei como resultante de uma luta. Ao contrário, elas estão aí para lembrarmos do porquê lutamos e onde efetivamente queremos chegar.

O texto aprovado no início de junho e sancionado pela Presidenta em 25 de junho de 2014, é o resultado desta disputa de interesses e concepções que permearam todo o processo que se estabeleceu pós Conae/2010. Está longe de ser uma lei de inteira adesão a um projeto de mudança no patamar de exclusão da população do acesso à educação de qualidade para todos, por outro lado introduz elementos importantes para a continuidade desta luta nas suas várias dimensões. 


\section{ALGUMAS CONSIDERAÇÕES FINAIS}

Voltando à palavra de ordem: "pessimismo da inteligência, otimismo da vontade", é importante que se reconheça que o principal desafio da década é fazer deste plano um instrumento político e pedagógico. Político porque coube o desafio da participação da comunidade educacional na construção, aprovação e implementação dos PEEs, PMEs, onde diga-se de passagem a presença dos pesquisadores nem sempre é tão intensa quanto o necessário, e na vigilância constante para sua implementação, inclusive no que concerne à compreensão do uso dos recursos públicos. Pedagógico porque é o exercício de aprender-fazendo, os enfrentamentos cotidianos necessários ao cumprimento e superação das metas, no âmbito das políticas educacionais.

Concluindo, estas reflexões, reiteramos que os desafios do PNE 2014-2014, nos últimos meses, podem se resumir em duas frentes. Uma dimensão política: ser a referência para a política educacional, em tempos de atravessamentos múltiplos entre as ações indutivas da Secretaria de Assuntos Estratégicos da Presidência da República (refiro-me aqui especificamente aos documentos publicados pelo Ministro Mangabeira Unger, já alvo de várias das nossas críticas), das várias secretarias e autarquias do MEC, com participação maior ou menor do FNE, do Conselho Nacional da Educação e do Congresso Nacional. Uma dimensão econômica: implementar estratégias das 20 metas do PNE sob forte impacto no orçamento da união, dos estados e municípios do contingenciamento dos recursos para a área da Educação. É uma conjuntura em que, de fato, não há muita clareza do que deve nos mover, se a compreensão gramsciana: pessimismo da inteligência, otimismo da vontade, ou, num cenário mais dramático, reconhecer como Lenine: Um passo em frente dois passos atrás. Em ambos os casos, para nós educadores cabe a compreensão de que temos um compromisso ético-político frente a esta conjuntura. A realidade não está dada, fazemos parte dela, e cabe a nós nos envolvermos de forma comprometida na sua construção. Creio que a realização deste III Colóquio, mantendo espaços de discussão e articulação entre sujeitos que buscam uma educação voltada para formação humana integral, revela pare do compromisso de todos nós com o enfrentamento das adversidades desta conjuntura. Agradeço a oportunidade de fazer parte deste coletivo.

\section{REFERÊNCIAS}

1. BRASIL. Instituto Brasileiro de Geografia e Estatística. Censo de 2010.

2. _ Ministério da Educação. Fundação Coordenação de Aperfeiçoamento de Pessoal de Nível Superior (CAPES). Plano Nacional de Pós-Graduação (PNPG 2011-2020). 2010.

3. Presidência da República. Lei no 4024 de 20 de dezembro de 1961 que fixa as Diretrizes e Bases da Educação Nacional.

4. Lei no 13.005 de 25 de junho de 2014 que aprova o Plano Nacional de Educação e dá outras providências.

5. CURY, Carlos Roberto Jamil. Direito a Educação: direito à igualdade, direito à diferença. In. : Cadernos de Pesquisa, n. 116, p. 245-262, julho/ 2002.

6. GRAMSCl, Antonio. Cadernos do Cárcere. Volume 1. Rio de Janeiro: Civilização Brasileira, 1999.

7. . Cadernos do Cárcere. Volume 3. Rio de Janeiro: Civilização Brasileira, 2000. 